\title{
STUDY OF DETERMINANTS OF AGE-RELATED MACULAR DEGENERATION IN THE 50 YEARS AND OLDER POPULATION- A COMPARATIVE STUDY
}

\author{
Manoj Mehta1, Richa Sharma², Shubhra Mehta ${ }^{3}$
}

1 Professor and HOD, Department of Ophthalmology, R. D. Gardi Medical College, Ujjain, Madhya Pradesh, India.

2Postgraduate Student, Department of Ophthalmology, R. D. Gardi Medical College, Ujjain, Madhya Pradesh, India.

3Professor, Department of Ophthalmology, R. D. Gardi Medical College, Ujjain, Madhya Pradesh, India.

\begin{tabular}{l}
\hline ABSTRACT \\
BACKGROUND \\
To study the determinants of Age-Related Macular Degeneration in the 50 years and older population. Combating blindness has \\
always been a challenge to all ophthalmologists all over the world. Age-related macular degeneration (ARMD) along with cataract \\
and glaucoma, form a significant triad of aetiology associated with development of blindness. We wanted to study the determinants \\
of age-related macular degeneration in the 50 years and older population.
\end{tabular}

\section{METHODS}

Ours was a comparative study of 218 patients. Patients were divided into 2 groups. 109 patients with Age-Related Macular Degeneration were in Group 1 whereas 109 patients without Age-Related Macular Degeneration were in Group 2 (Control Group). All patients underwent a comprehensive ocular examination as well as retinal evaluation. Detailed lab investigations further helped us in reaching to the probable factors associated with age-related macular degeneration.

\section{RESULTS}

144 patients (66\%) out of 218 patients were in the age group of 61-80 years. Our study had 115 females (52.8\%) as compared to 103 males (47.2\%). 76.1\% patients were residing in rural areas, hypertension was associated in 36 (33\%), smoking was seen in 28 (12.8\%) patients. Dyslipidaemia, hypertension, renal diseases, alcohol intake, exposure to sunlight were other associated determinants of age-related macular degeneration in our study.

\section{CONCLUSIONS}

Results of our study shows that all elderly persons coming with diminution of vision should be screened for age-related macular degeneration and determinants of age-related macular degeneration should also be kept in mind while managing the patients of age-related macular degeneration.

HOW TO CITE THIS ARTICLE: Mehta M, Sharma R, Mehta S. Study of determinants of age-related macular degeneration in the 50 years and older population- a comparative study. J. Evolution Med. Dent. Sci. 2019;8(13):1074-1077, DOI: $10.14260 /$ jemds/2019/237

\section{BACKGROUND}

Combating blindness has always been a challenge to all ophthalmologists all over the world. Age-related macular degeneration (ARMD) along with cataract and glaucoma form a significant triad of aetiology associated with development of blindness. All efforts should be made to make an early diagnosis of Age-related macular degeneration (ARMD), so that patients can be treated properly, and we can try our best to improve the quality of vision in patients suffering from Age-related macular degeneration (ARMD).

The prevalence of age-related macular degeneration increases with age, increasing to $2.6 \%$ in $51-60$ years of age, $6.5 \%$ in $61-70$ years and to $19.3 \%$ among subjects above 71 years. ${ }^{1}$

There are many risk factors associated with age-related macular degeneration like increasing age, female gender, blue

'Financial or Other Competing Interest': None.

Submission 03-01-2019, Peer Review 18-03-2019,

Acceptance 25-03-2019, Published 01-04-2019.

Corresponding Author:

Richa Sharma,

48/110, Purvi Hosptial,

Rajat Path, Mansarovar,

Jaipur,

Rajasthan, India.

E-mail: richasharma22jan@gmail.com

DOI: $10.14260 /$ jemds/2019/237

\section{(c) (i) $(9)$}

eyed patients, smoking, genetic predisposition, exposure to ultra-violet light, hence our study was planned to study these determinants of age-related macular degeneration in elderly people.

\section{METHODS}

The comparative study was conducted in the Department of Ophthalmology of R. D. Gardi Medical College, Ujjain. Our study included 218 patients and it was a hospital-based study. The ethical approval for study was taken from institutional ethics committee. All the data of the patient was collected, entered in a pretested proforma and analysed in detail.

\section{Selection Criteria}

Patients more than 50 years of age and more were included in the study. 109 patients who were suffering from agerelated macular degeneration were included in Group 1 whereas, Group 2 (control group) included 109 patients without age-related macular degeneration. Study included total 218 patients. This was a hospital-based study conducted in Ophthalmology Out-patient department.

\section{Study Design}

Our study was a comparative study of 218 patients aged 50 years or more. This study was based on source of patients were patients reporting to the eye OPD of our department. 
Patients were divided into 2 groups-

1. Group 1 (109 patients) who had age-related macular degeneration

2. Group 2 (109 patients) who did not have age-related macular degeneration.

The study was conducted over a period of 1 year.

\section{Methodology}

Written informed consent was taken from all the patients who were enrolled in the study. All the patients underwent a detailed comprehensive ocular examination and the data was entered in a pretested proforma.

\section{Inclusion Criteria}

- Patients more than or equal to 50 years of age group.

- Patients consenting for participation in study.

\section{Exclusion Criteria}

- Patients with hazy ocular media where retinal examination is not possible.

- Patients with renal disorders.

- Pregnant woman.

Detailed and comprehensive ocular examination was done for all patients. Fundus examination including direct ophthalmoscopy, indirect ophthalmoscopy, and fundus photographs were taken by Topcon fundus camera. Fundus fluorescein angiography was done in all the patients. IOP was recorded for all the patients.

Lab investigations like haemoglobin, random blood sugar were also recorded. Blood pressure, anaemia, diabetes, were found to be associated with determinants of age-related macular degeneration

A proper diagnosis of each patient was made categorizing them in either dry or wet age-related macular degeneration.

Each patient was managed either by conservative method or glasses, antioxidants, Low vision aids or AntiVEGF. Follow up of all the patients was done at an interval of 4 weeks and 12 weeks for all cases and controls.

\section{Statistical Analysis}

All the data of our study was analysed during SPSS 20.0 statistical software (SPSS Inc. Chicago, IL).

\section{RESULTS}

Our study was a comparative study of 218 patients aged 50 years or more Patients in our study group were divided into 2 groups - 109 patients with age-related macular degeneration were in group 1 whereas group 2 (Control Group) included 109 patients without age-related macular degeneration.

Out of 218 patients, 74 (33.9\%) were in age group 50-60 years whereas $89(40.9 \%)$ were in age group 61-70 years and $55(25.2 \%)$ patients were in age group 71-80 years.
Out of 218 patients, $103(47.2 \%)$ patients were male patients with 50 males in group 1 and 53 in group 2 and 115 (52.8\%) patients were female with 59 in group 1 and 56 females in group 2 as shown in the table No. 1. Females were found to be more predisposed to development of age-related macular degeneration. (Chi-square value $=0.1656, \mathrm{p}$ value $=$ 0.684 , $p$ value $<0.05$ was considered significant in our study.)

\begin{tabular}{|c|c|c|c|c|c|}
\hline Sl. No. & Sex & Group 1 & Group 2 & Total & Percentage (\%) \\
\hline 1. & Male & 50 & 53 & 103 & $47.2 \%$ \\
\hline 2. & Female & 59 & 56 & 115 & $52.8 \%$ \\
\hline & Total & 109 & 109 & 218 & 100.0 \\
\hline
\end{tabular}

$166(76.1 \%)$ patients were from the rural area and 52 (23.9\%) patients belonged to urban area (Chi square value= 4.95 , $p$ value $=0.026$ ). This distribution was mainly due to the fact that our college is situated in rural area of Central India.

$58(26.6 \%)$ patients in the study group had raised blood pressure which shows that raised blood pressure is one of the strongest determinants of age-related macular degeneration. 12 patients in the study group had Hb levels $<8 \mathrm{gm} \%$. This result of our study shows that anaemia is also one of the factors associated with development of age-related macular degeneration.

19 (17.4\%) patients in group 1 had abnormal lipid levels whereas only 12 (11\%) had abnormal lipid levels in group 2. This result signifies that dyslipidaemia is a strong risk factor associated with age-related macular degeneration.

Out of 218 eyes in group 1, dry age-related macular degeneration was seen in 149 (68.34\%) eyes whereas wet age-related macular degeneration was seen in 60 (27.56\%) eyes as shown in Figure No. 1.

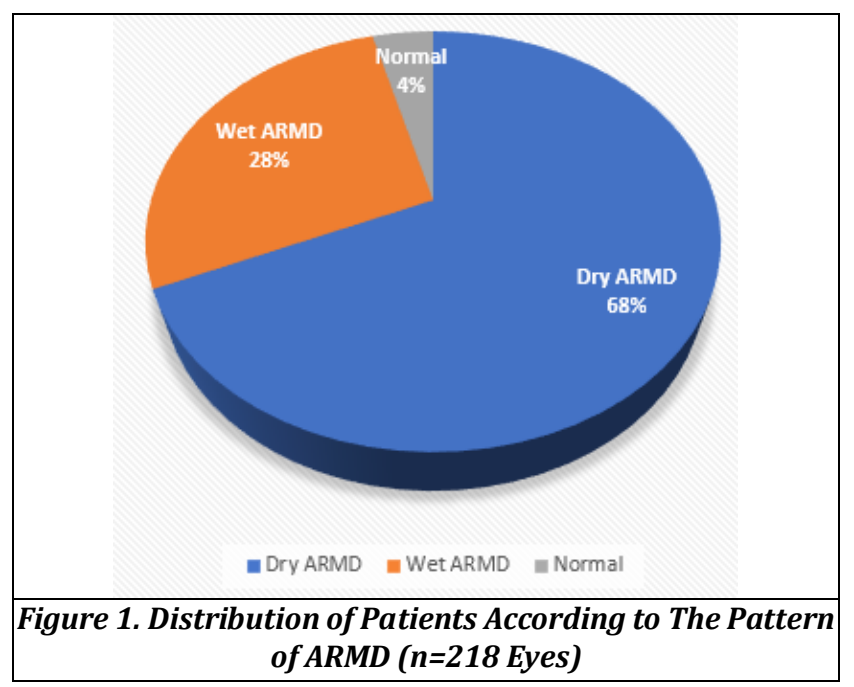

In our study we found that there are many risk factors associated with age-related macular degeneration like hypertension, renal disease, smoking, anaemia, dyslipidaemia, cardiac abnormality, thyroid dysfunction, alcohol intake, exposure to sunlight as shown in Table No. 2 . 


\begin{tabular}{|c|c|c|c|c|c|c|}
\hline $\begin{array}{c}\text { Associated } \\
\text { Risk Factors }\end{array}$ & $\begin{array}{c}\text { Group } \\
1\end{array}$ & $\begin{array}{l}\text { Group } \\
\quad 2\end{array}$ & Total & (\%) & $\begin{array}{c}\mathbf{z}^{-} \\
\text {Test }\end{array}$ & $\begin{array}{c}\text { p- } \\
\text { Value }\end{array}$ \\
\hline Hypertension & 36 & 22 & 58 & 26.6 & 2.14 & 0.03 \\
\hline Renal Disease & 6 & 8 & 14 & 6.4 & 0.552 & 0.582 \\
\hline Smoking & 17 & 11 & 28 & 12.8 & 1.22 & 0.226 \\
\hline Anaemia & 3 & 9 & 12 & 5.5 & 1.78 & 0.075 \\
\hline Dyslipidaemia & 19 & 12 & 31 & 14.2 & 1.35 & 0.173 \\
\hline $\begin{array}{c}\text { Cardiac } \\
\text { Abnormality }\end{array}$ & 8 & 12 & 20 & 9.2 & 0.938 & 0.347 \\
\hline $\begin{array}{c}\text { Thyroid } \\
\text { Dysfunction }\end{array}$ & 2 & 3 & 5 & 2.3 & 0.452 & 0.652 \\
\hline Alcohol Intake & 8 & 24 & 32 & 14.7 & 3.06 & 0.002 \\
\hline $\begin{array}{l}\text { Exposure to } \\
\text { Sunlight }\end{array}$ & 10 & 8 & 18 & 8.3 & 6.492 & 0.624 \\
\hline Total & 109 & 109 & 218 & 100 & & \\
\hline \multicolumn{7}{|c|}{$\begin{array}{c}\text { Table 2. Distribution of Cases According to Associated } \\
\text { Risk Factors of ARMD }\end{array}$} \\
\hline
\end{tabular}

Age-related macular degeneration directly affects the visual functioning of the individual and is one of the leading causes of blindness. In our study we found that $74(17 \%)$ eyes had visual acuity $<3 / 60$, whereas 184 eyes $(71.2 \%)$ had Visual acuity between $3 / 60-6 / 18$ as shown in Table No.3.

\begin{tabular}{|c|c|c|c|c|c|}
\hline $\begin{array}{c}\text { Sl. } \\
\text { No. }\end{array}$ & $\begin{array}{c}\text { Visual } \\
\text { Acuity }\end{array}$ & $\begin{array}{c}\text { RE (No. } \\
\text { of Eyes) }\end{array}$ & $\begin{array}{c}\text { LE (No. of } \\
\text { Eyes) }\end{array}$ & $\begin{array}{c}\text { Total (No. } \\
\text { of Eyes) }\end{array}$ & $\begin{array}{c}\text { Total } \\
\text { (\%) }\end{array}$ \\
\hline 1 & $<3 / 60$ & 51 & 23 & 74 & 17 \\
\hline 2 & $3 / 60-6 / 60$ & 28 & 43 & 71 & 16.3 \\
\hline 3 & $6 / 36-6 / 24$ & 58 & 55 & 113 & 25.9 \\
\hline 4 & $6 / 18-6 / 12$ & 39 & 46 & 85 & 19.5 \\
\hline 5 & $6 / 9-6 / 6$ & 42 & 51 & 93 & 21.3 \\
\hline & Total & $\mathbf{2 1 8}$ & $\mathbf{2 1 8}$ & $\mathbf{4 3 6}$ & $\mathbf{1 0 0}$ \\
\hline
\end{tabular}

Table 3. Unaided Visual Acuity Distribution in Study Group (n=436 Eyes)

Majority of patients in group 1, 91 (83.48\%) patients were kept on Antioxidants, only 4 (3.66\%) patients required Anti-VEGF while 2 (1.83\%) patients underwent Laser photocoagulation as seen in Table No.4

\begin{tabular}{|c|c|c|}
\hline Treatment Done & Number of Patients & (\%) \\
\hline Glasses Prescribed & 12 & 11 \\
\hline Antioxidants & 91 & 83.48 \\
\hline Anti-VEGF & 4 & 3.66 \\
\hline Laser Photocoagulation & 2 & 1.83 \\
\hline Total & $\mathbf{1 0 9}$ & $\mathbf{1 0 0}$ \\
\hline Table 4. Management of Patients in Group 1 \\
(n=109 Patients)
\end{tabular}

\section{DISCUSSION}

Age-related macular degeneration is one of the leading causes of visual impairment in elderly persons.

Age-related macular degeneration directly influences the working capabilities of an individual and this then directly affects the whole family and the society.

Our study was a comparative study which was designed to study the determinants of age-related macular degeneration, in patients aged 50 years or more. Written informed consent was taken from all the patients who were enrolled in the study. In our study we found that 74 patients (33.9\%) belonged to age group 50-60 years, 89 patients $(40.9 \%)$ belonged to age group 61-70 years and 55 patients (25.2\%) belonged to age group 71-80 years.
This result of our study is comparable with the study of Vinding et al who found in their study that the prevalence of age-related macular degeneration increased with rising age for both sexes: age group 60-64 years: $2.3 \%, 65-69: 5.9 \%, 70-$ $74: 12.1 \%$ and $75-80: 27.3 \% .^{2}$

There is potentially higher risk of neovascular age-related macular degeneration for women. ${ }^{3}$

We in our study also found that out of 109 patients suffering from age-related macular degeneration, 59 patients (54\%) were females.

Hypertension was associated in 36 patients (33\%) with age-related macular degeneration as compared to 22 patients $(20.18 \%)$ in group 2. Difference was significant and this shows that hypertension was a significant factor associated with age-related macular degeneration.

Results of our study correlated with study of Klein et al who also found that high systolic blood pressure were related with the development of age-related macular degeneration. ${ }^{4}$

Krishnaiah et al found the incidence of age-related macular degeneration to be $14 \%$ in smokers. We in our study also found that $12.8 \%$ of our patients with age-related macular degeneration were smokers. Smoking was associated in 17 patients (15.59\%) in Group 1 as compared to 11 patients $(10.09 \%)$ in Group 2.5

We in our study found 32 patients (14.7\%) had history of alcohol consumption which correlate with the study of Adam's et al who also suggested that alcohol consumption is significantly associated development of age-related macular degeneration. ${ }^{6}$

10 patients $(9.17 \%)$ in group 1 had history of exposure to sunlight. And this result of our study is in correlation with the study of Taylor et al who also suggested that exposure to sunlight is a factor for development of age-related macular degeneration. ${ }^{7}$

Tan et al in the study stated that dyslipidaemia is a very significant factor associated with development of age-related macular degeneration. We also found that 19 patients (17.43\%) had associated dyslipidaemia in Group 1 as compared to 12 patients (11\%) in group 2.8

We found that $5.5 \%$ of our patients in group 1 had renal disease associated with age-related macular degeneration. This result correlated with the study of Liew et al who also found that $17.5 \%$ of the patients with age-related macular degeneration had moderate kidney disease. ${ }^{9}$

17 patients $(15.6 \%)$ in group 1 of our study were diabetic. Topouzis et al in their study found the positive association of diabetes with Wet age-related macular degeneration. ${ }^{10}$

In our study 56 eyes (25.68\%) in group 1 had visual acuity $<3 / 60$ while in group 2 only 18 eyes (8.25\%) had visual acuity $<3 / 60$.

Hyman et al found in their study that Wet age-related macular degeneration leads to $90 \%$ of severe visual loss. ${ }^{11}$

Our study suggest that age-related macular degeneration is a leading cause of blindness and all possible efforts should be made to identify the associated risk factors to control the progression of age-related macular degeneration. Antioxidants play a major role in decreasing the progression of the disease.

\section{CONCLUSIONS}

Age-Related Macular Degeneration is the leading cause of blindness. Hypertension, smoking, dyslipidaemia, exposure to 
sunlight, alcohol intake, renal disease, diabetes, are strong determinants of age-related macular degeneration as found in our study.

Management of age-related macular degeneration should encompass a comprehensive view of the disease (the pattern of age-related macular degeneration, associated risk factors, the visual impairment caused by age-related macular degeneration). Early detection and proper management of age-related macular degeneration is very essential to decrease the incidence of blindness from age-related macular degeneration.

\section{REFERENCES}

[1] Pokharel S, Malla OK, Pradhananga CL, et al. A pattern of age-related macular degeneration. JNMA Journal of the Nepal Medical Association 2009;48(175):217-20.

[2] Vinding T. Age-related macular degeneration. Macular changes, prevalence and sex ratio. Acta Ophthalmologica (Copenh) 1989;67(6):609-16.

[3] Rudnicka AR, Jarrar J, Wormald R, et al. Age and gender variations in age-related macular degeneration prevalence in populations of European ancestry: a meta-analysis. Ophthalmology 2012;119(3):571-80.

[4] Klein R, Klein BE, Jensen SC. The relation of cardiovascular disease and its risk factors to the 5year incidence of age-related maculopathy: the Beaver Dam Eye Study. Ophthalmology 1997;104(11):180412.
[5] Krishnaiah S, Das T, Nirmalan PK, et al. Risk factors for age-related macular degeneration: findings from the Andhra Pradesh eye disease study in South India. Invest Ophthalmol Vis Sci 2005;46(12):4442-9.

[6] Adams MK, Chong EW, Williamson E, et al. 20/20Alchol and age-related macular degeneration. The Melbourne Collaborative Cohort Study Am J Epidemiol 2012;176(4):289-98.

[7] Taylor HR, Munoz B, West S, et al. Visible light and risk of age-related macular degeneration. Transactions of the American Ophthalmological Society 1990;88:16378.

[8] Tan JSL, Mitchell P, Smith W, et al. Cardiovascular risk factors and the long term incidence of age-related macular degeneration: the Blue Mountains Eye Study. Ophthalmology 2007;114(6):1143-50.

[9] Liew G, Mitchell P, Wong TY, et al. CKD increases the risk of age-related macular degeneration. Journal of the American Society of Nephrology 2008;19(4):80611.

[10] Topouzis F, Anastasopoulos E, Augood C, et al. Association of diabetes with age-related macular degeneration in the EUREYE study. Br J Ophthalmol 2009;93(8):1037-41.

[11] Hyman L, Schachat AP, He Q, et al. Hypertension, cardiovascular disease and age-related macular degeneration. Age-Related Macular Degeneration Risk Factors Study Group. Arch Ophthalmol 2000;118(3):351-8. 